\title{
Evaluating and ranking decision making units in the two-stage network DEA based on reference frontier
}

\author{
elham abdali ${ }^{1}$ and Reza Fallahnejad ${ }^{2}$ \\ ${ }^{1}$ Islamic Azad University of Khorramabad, Khorramabad, Lorestan Province, \\ ${ }^{2}$ Islamic Azad University Khorramabad Branch Faculty of Basic Sciences
}

February 21, 2022

\begin{abstract}
The present study proposes a method for evaluating and ranking the efficiency of decision-making units (DMUs) that has a two-stage network structure in data envelopment analysis (DEA). Measuring the efficiency of two-stage network systems in data envelopment analysis has developed considerably, but ranking it in a logical and accurate analysis is a subject that still needs further study. In the present study, a model is presented that can consider the impact of each efficient DMUs on the whole two-stage network system, as well as using the reference frontier, the impact of each efficient DMUs in each evaluating nonefficient DMUs. It also provided more information to rank and identify the impact of extreme efficient DMUs on non-efficient DMUs by reference frontier. The concept of reference frontier introduced in the present study has the potential to determine the contribution of each extreme efficient DMUs in constructing a reference frontier for each non-extreme efficient DMUs and non-efficient DMUs. These facts have been investigated using logical reasoning and proof of several theorems, and have been discussed with a Practical example.
\end{abstract}

\section{Hosted file}

reference frontier.docx available at https://authorea.com/users/461582/articles/557246evaluating-and-ranking-decision-making-units-in-the-two-stage-network-dea-based-onreference-frontier

\section{Hosted file}

Cover.docx available at https://authorea.com/users/461582/articles/557246-evaluating-andranking-decision-making-units-in-the-two-stage-network-dea-based-on-reference-frontier 